\title{
Staining of esthetic brackets by plaque disclosing solutions
}

\author{
Luiza Novelino Acatauassú Ismael ${ }^{1}$, Mauro de Amorim Acatauassú Nunes², Ana Maria Novelino Acatauassú Nunes ${ }^{3}$, \\ Rogério Heládio Lopes Motta ${ }^{4}$, Ana Paula Dias Demasi ${ }^{5}$, Flávia Martão Flório ${ }^{6}$ \\ ${ }^{1}$ Universidade Federal do Pará - UFPA, School of Dentistry, Department of Orthodontic, Belém, PA, Brazil \\ ${ }^{2}$ Universidade Federal do Pará - UFPA, School of Dentistry, Department of Traumatology, Belém, PA, Brazil \\ ${ }^{3}$ Associação Brasileira de Odontologia - ABO, Area of Pediatric Dentistry, Belém, PA, Brazil \\ ${ }^{4}$ Faculdade São Leopoldo Mandic - SLMANDIC, Dental School and Research Center, Department of Pharmacology, Anesthesiology and Therapeutics, \\ Campinas, SP, Brazil \\ ${ }^{5}$ Faculdade São Leopoldo Mandic - SLMANDIC, Dental School and Research Center, Department of Pathology, Campinas, SP, Brazil \\ ${ }^{6}$ Faculdade São Leopoldo Mandic - SLMANDIC, Dental School and Research Center, Department of Dental Public Health, Campinas, SP, Brazil
}

\begin{abstract}
Aim: To evaluate the staining of esthetic orthodontic brackets by plaque disclosing solutions. Methods: Two types of brackets manufactured by GAC/DENTSPLY ${ }^{\circledR}$ were evaluated: ceramic $(n=30)$ and polycarbonate $(n=30)$. The brackets were divided into 6 groups. Two control groups $(n=6)$ were immersed in absolute ethanol: $\mathrm{Gl}$ - ceramic brackets and $\mathrm{GIl}$ - polycarbonate brackets. Four experimental groups $(n=12)$ were immersed in different plaque disclosing solutions: GIII (ceramic brackets) and GIV (polycarbonate brackets) were immersed in Replak ${ }^{\circledR}$; GV (ceramic brackets) and GVI (polycarbonate brackets) were immersed in Replasul "S" ${ }^{\circledR}$. Relative quantitative analysis of the influence of plaque disclosing tablets on bracket staining was performed using reflectance spectrophotometry of stain deposition. Exploratory analysis of the data was performed using Analysis of Variance (ANOVA) in a $2 \times 2$ factorial setup (bracket $\mathrm{x}$ immersion) with additional treatments (controls). Results: The results demonstrated that the ceramic brackets presented the highest amount of staining when Replasul "S" ${ }^{\circledR}$ was used (pd"0.05). However, when Replak ${ }^{\circledast}$ was used, no statistically significant difference was found in comparison with the control group ( $p>0.05)$. For polycarbonate brackets, staining was detected for both disclosing solutions $(p>0.05)$. Conclusions: The disclosing solutions caused stain formation on polycarbonate brackets and, under the tested conditions, use of Replak ${ }^{\circledast}$ on ceramic brackets did not cause staining.
\end{abstract}

Keywords: orthodontic brackets; spectrophotometry; biofilms.

\section{Introduction}

The strategy of applying a tailored preventive program for each patient, considering both the risk to plaque-related disease and the level of adherence to

Received for publication: April 23, 2014 Accepted: June 09, 2014

Correspondence to:

Flávia Martão Flório

Rua José Rocha Junqueira, 13 - Bairro Swift

CEP: 13041-445 Campinas, SP, Brazil

Phone: + 551932113650

E-mail: flaviaflorio@yahoo.com the necessary measures, is mandatory for a satisfactory correction of occlusion without compromising the oral tissue health ${ }^{1-3}$.

The dental materials industry has been investing in manufacturing custom brackets that combine both adequate esthetics and technical performance ${ }^{4}$.

The first esthetic brackets developed in the 1960 s were made of polycarbonate ${ }^{5}$, which presented disadvantages in terms of clinical performance such as deformation, structural fragility, low adhesion and superficial staining ${ }^{6-8}$. Consequently, the use of such appliances was recommended with caution and was limited to short 
times of treatment. These materials present unique features that must be fully understood by orthodontists so they can prescribe them safely, taking the adequate clinical care to select the cases that would benefit most from the treatment with esthetic brackets 9 .

Ceramic orthodontic brackets were first made available in the late 1980s with the aim of eliminating the esthetic issue imposed by metallic brackets and the disadvantages of polycarbonate brackets. The early appliances represented significant clinical and esthetic advances due to their shade stability and resistance to oral fluids ${ }^{10-15}$.

The advantages and disadvantages of polycarbonate and ceramic brackets have been investigated in vitro, especially in terms of changes in optical properties due to discoloration and staining-by pigmented substances from foods and drinks ${ }^{9,16-20}$. The latter aspect is of great importance to orthodontists as patients become increasingly demanding of appliances that do not show and remain as such, especially in terms of shade, $16,21-25$. The optical properties of esthetic brackets have a direct influence on visual perception ${ }^{26}$.

Once bonded, brackets make oral hygiene more difficult and may serve as a retention sites for stagnation of foods and bacterial biofilm accumulation, increasing the risk of enamel demineralization and periodontal problems ${ }^{27}$.

Mechanical plaque removal using a toothbrush is the bestknown and readily available method for prevention and control of such problems, which may be effective if performed appropriately. Plaque disclosing substances should also be part of the educational process, since they play a fundamental role of guiding and motivating orthodontic patients to tooth brushing, and among the available plaque disclosing solutions, basic fuchsine and Replak ${ }^{\circledR}$ are largely used in clinical practice ${ }^{28}$.

The purpose of tooth brushing should not be limited to the automatic and mechanical fulfillment of a mere cosmetic ritual, but it must achieve an adequate disorganization of the bacterial biofilm. Passing this message across clearly to the patients, so that they are motivated throughout the course of orthodontic treatment, is no easy task. Effective communication between patients, parents, orthodontists and general dental practitioners must be in place in order to reduce the incidence of white lesions in patients wearing fixed orthodontic appliances ${ }^{29}$.

Studies on the possible shade changes caused by known pigmented solutions such as Coca-Cola ${ }^{\circledR}$, tea, coffee, red wine, etc. to polycarbonate and ceramic brackets have been performed $^{17,21}$. There is, however, a lack of reports on the degree of staining of such appliances by plaque disclosing solutions. This could partially explain why most orthodontists avoid procedures of plaque disclosure prior to prophylaxis and patients prior to brushing, in other words, there is no scientific evidence that such dyes will not cause staining of polycarbonate and ceramic brackets.

The purpose of this study was to evaluate whether esthetic brackets are stained by different plaque disclosing solutions.

\section{Material and methods}

The study sample was composed by 60 esthetic brackets,
30 ceramic and 30 polycarbonate, from GAC/Dentsply (Islandia, NY, USA) for the maxillary right central incisor (11).

The brackets were divided into 2 control groups $(n=6)$ and 4 experimental groups $(\mathrm{n}=12)$. Two disclosing solutions Replak $^{\circledR}$ (Dentisply, Petrópolis/RJ, Brazil), based on red and blue food dyes and Replasul " $\mathrm{S}$ " (Iodontosul, Porto Alegre/ RS, Brazil), based on $0.04 \%$ basic fuchsine] and two types of esthetic brackets [ceramic (Mystique $\mathrm{Mb}^{\circledR}$, Dentsply/GAC, Bohemia, NY)] or polycarbonate (Elation $\mathrm{Mb}^{\circledR}$, Dentsply/GAC, Bohemia, NY) were used. The groups were named GI (control), esthetic ceramic brackets immersed in absolute ethanol; GII (control), esthetic polycarbonate brackets immersed in absolute ethanol; GIII, esthetic ceramic brackets immersed in Replak $^{\circledR}$, GIV; esthetic polycarbonate brackets immersed in Replak ${ }^{\circledR} ; \mathrm{GV}$, esthetic ceramic brackets immersed in Replasul "S" ${ }^{\circledR}$; and GVI, esthetic polycarbonate brackets immersed in the plaque disclosing solution Replasul " $\mathrm{S}$ "

The relative quantitative analysis of the influence of plaque disclosing solutions on shade changes of brackets by stain deposition was performed using Reflectance Spectrophotometry ${ }^{17,21,30-31}$. An amount of $250 \mathrm{iL}$ of each dye and ethanol was pipetted into the wells of a 96-well plate. In order to avoid cross-contamination of dyes through spillage, the pipetting sequence was: Replak ${ }^{\circledR}$, Replasul “ $\mathrm{S}$ ” ${ }^{\circledR}$ and ethanol.

Each well received one type of bracket using dental tweezers. All brackets remained immersed in ethanol (control group) and in their respective plaque disclosing solution for $1 \mathrm{~h}$. The plates were kept at room temperature in the dark, preventing the interference of light in shade change of the brackets $^{17,21}$.

The test specimens were removed using a pair of tweezers and rinsed in distilled water by immersion for $15 \mathrm{~s}$ in the appropriate well of a 24 -well plate ${ }^{17,21,30}$. The brackets were subsequently dried in absorbent paper for $1 \mathrm{~min}$, always following a random sequence $\mathrm{e}^{30-31}$.

The brackets were then immersed in 250 iL absolute ethanol in the wells of a 96-well plate ${ }^{30-31}$ which was placed in an orbital shaker (Biomixer, Chatswood, NSW, Australia) for $24 \mathrm{~h}$ to elute the dye that was deposited onto the specimen. The brackets were removed from the wells and the plate was placed in a reflectance spectrophotometer (Epoch - Biotek ${ }^{\mathrm{TM}}$ Instruments, Inc., Winooski, VT, USA) to quantify and observe the degree of absorbance of the experimental solutions, which was registered and printed using the Gen 5TM Getting Started Guide (Biotek ${ }^{\mathrm{TM}}$ Instruments, Inc. - Dec. 2009) software. Readings were taken from the absorption spectrum peaks, since each dye showed better results at different wavelengths. The readings for each solution were compared against the control group within the same absorbance spectrum ${ }^{30-31}$.

In order to establish the relationship between the absorbance of the red and blue solutions $\left(\right.$ Replak $\left.^{\circledR}\right)$ and $0.04 \%$ basic fuchsine (Replasul " $\mathrm{S}$ " ${ }^{\circledR}$ ), the spectrophotometer was calibrated at the of 600 and $550 \mathrm{~nm}$ wavelengths, respectively (maximum absorbance spectrum of each solution).

The exploratory analysis of the data required a square root adjustment so that the values fulfilled the assumptions 
of a parametric analysis. Analysis of Variance (ANOVA) was then applied using a $2 \times 2$ factorial setup (bracket $\mathrm{x}$ immersion) and additional treatments (control groups). For Replak ${ }^{\circledR}$, ethanol measured at a wavelength of $600 \mathrm{~nm}$ was considered, whilst for Replasul " $\mathrm{S}$ " , ethanol was measured at $550 \mathrm{~nm}$, always with the respective bracket type. The comparisons with the controls were performed using the Dunnett's test with $p=0.05$. All analyses were performed using the statistics SAS software (SAS Inc., Cary, NC, USA).

\section{Results}

Table 1 shows the amount of staining of the studied esthetic brackets. For the ceramic brackets, the highest degree of staining was observed with Replasul " $\mathrm{S}$ " ${ }^{\circledR}(\mathrm{p} \leq 0.05)$, whereas for the polycarbonate brackets no significant difference was found between the tested disclosing solutions $(p>0.05)$, but staining was observed for both products.

Regarding the plaque disclosing solutions, Replak ${ }^{\circledR}$ on polycarbonate brackets caused the highest average stain readings $(\mathrm{p} \leq 0.05)$. The use of $\operatorname{Replak}^{\circledR}$ on ceramic brackets did not show statistically significant difference against the control group $(\mathrm{p} \leq 0.05)$.

Table 1. Mean staining (standard deviation) according to type of bracket and immersion solution

\begin{tabular}{lll}
\hline Immersion & \multicolumn{2}{c}{ Bracket type } \\
\cline { 2 - 3 } & Ceramic & Polycarbonate \\
Ethanol (550 nm control Replasul) & $0.08(0.06)$ & $0.06(0.02)$ \\
Ethanol (600 nm control Replak) & $0.06(0.03)$ & $0.05(0.01)$ \\
Replak & $0.11(0.05) \mathrm{Bb}$ & $* 0.17(0.07) \mathrm{Aa}$ \\
Replasul "S" & ${ }^{*} 0.27(0.06) \mathrm{Aa}$ & $* 0.19(0.09) \mathrm{Ba}$
\end{tabular}

Means followed by different letters (uppercase horizontally and lowercase vertically) indicate significant difference $(p<0.05)$. * Different from the ethanol group for the same bracket type $(p<0.05)$.

\section{Discussion}

The present study assessed the shade changes caused by plaque disclosing solutions on polycarbonate and ceramic brackets using reflectance spectrophotometry. This method aims to determine the concentration of a substance generally present in a solution, using a known concentration of the same compound as a reference ${ }^{31}$. It is a method previously used to quantify a dye that impregnates specimens ${ }^{17,21,30-31}$ and it is in an anatycal technique to quantitatively determine chemical species.

The results demonstrated that the use of a fuchsine-based plaque disclosing solution (Replasul " $\mathrm{S}$ " ${ }^{\circledR}$ ) caused the ceramic bracket to present the highest degree of staining, however, when Replak ${ }^{\circledR}$ was used, no difference was observed when compared with the control group, suggesting that this disclosing solution was not adsorbed onto the bracket surface in the time adopted for this study, thus causing no shade change to the bracket. Therefore, the use of Replak $^{\circledR}$ on ceramic brackets did not cause staining, suggesting it as the plaque disclosing solution of choice for patients undergoing orthodontic treatment. Previous studies have reported that ceramic brackets are stain and discoloration resistant to any chemical substance encountered in the oral environment, which contradicts the findings from this study ${ }^{10-13,23}$.

Esthetic material can undergo shade or color change due to both extrinsic and intrinsic factors. According to some authors ${ }^{10,14,18-19,27}$ the intrinsic factors include the material discoloration itself, as a result of matrix changes (ageing, physicochemical conditions such as visible light radiation, ultraviolet rays and moisture) and the extrinsic factors include absorption and adsorption of substances. Consequently, it is possible to infer that the fuchsine-based disclosing solution bonded to the ceramic both intrinsically and extrinsically via incorporation of the dye into the bracket. The food dyes present in Replak $^{\circledR}$, however, did not show intrinsic or extrinsic affinity to the ceramic when compared with the control group, thus making it the plaque disclosing product of choice for patients wearing esthetic ceramic brackets. This corroborates other reports on the esthetic advantages of ceramic over polycarbonate brackets 9 14,16,18-22,24-25,27; however, ceramic brackets can also be stained $^{30}$. According to a study that evaluated the chromatic changes of some types of ceramic brackets, the results demonstrated that the discolorations were significant when time was taken into account for all tested solutions ${ }^{17}$.

This study demonstrated the staining of polycarbonate brackets by both disclosing solutions Replasul " $\mathrm{S}$ " ${ }^{\circledR}$ and Replak $^{\circledR}$, showing that shade or color change by extrinsic physicochemical factors were observed in this type of material. Another study reported clinical problems with discoloration when using polycarbonate brackets even in the absence of a dye $^{18}$, despite the excellent hardness of such resin material, thus corroborating the results from this study.

As reported in the literature, polycarbonate and ceramic brackets have different patterns of color or shade change for each solution used $6-9,14,16,18,22,24-25,27$. The present study corroborates those findings in terms of changes to optical properties of such brackets in the oral environment, as a result of staining by coloring substances present in foods and beverages ${ }^{9,16-17,21-22,24-25 . ~}$

The planning of orthodontic treatment either due to esthetics or for oral health purpose ${ }^{3,13}$ must include strategies of plaque control and, the use of plaque disclosing solutions must not be dismissed from the motivational arsenal and home care kit. Therefore, further studies are needed on the factors that interfere with color and shade stability of such devices, since the demand for more discrete appliances increases rapidly, just as the optical properties of esthetic brackets are the least investigated directly ${ }^{9}$.

This study demonstrated that plaque disclosing agents might interfere with bracket shade. The choice of the most appropriate product for each bracket type should be cautious. The findings from this study suggest that patients wearing ceramic brackets ought to opt for Replak ${ }^{\circledR}$. The tested plaque disclosing products caused color changes on polycarbonate brackets, which should be further investigated clinically to determine its relevance for patients wearing such appliances. 
In conclusion, the plaque disclosing solutions tested in this study should not be used on polycarbonate brackets and, under the conditions described in this study, the use of Replak $^{\circledR}$ on ceramic brackets did not cause staining.

\section{References}

1. Derks A, Kuijpers-Jagtman AM, Frencken JE, Van't Hof MA. Caries preventive measures used in orthodontic practices: an evidence-based decision? Am J Orthod Dentofacial Orthop. 2007; 132: 165-70.

2. Behnan SM, Arruda AO, González-Cabezas C, Sohn W, Peters M. Invitro evaluation of various treatements to prevent demineralization next to orthodontic brackets. Am J Orthod Dentofacial Orthop. 2010; 138: 712.e1-7; discussion 712-3.

3. Mckiernan EXF, Mckiernan F, Jones ML. Psychological profiles and motives of adults seeking orthodontic treatment. Int J Adult Orthodon Orthognath Surg. 1992; 7: 187-98.

4. Jena AK, Duggal R, Mehrotra AK. Physical properties and clinical characteristics of ceramic brackets: a comprehensive review. Trends Biomater Artif Organs. 2007; 20: 101-5.

5. Newman GV. Adhesive and orthodontic plastic attachments. Am J Orthod Dentofacial Orthop. 1969; 56: 573-88.

6. Dobrin RJ, Kamel IL, Musich DR. Load-deformation characteristics of polycarbonate orthodontic brackets. Am J Orthod. 1975; 67: 24-33.

7. Eliades T, Lekka M, Eliades G, Brantley WA. Surface characterization of ceramic brackets: A multi-technique approach. Am J Orthod Dentofacial Orthop. 1994; 105: 10-8.

8. Feldner JC, Sarkar NK, Sheridan JJ, Lancaster DM. In vitro torquedeformation characteristics of orthodontic polycarbonate brackets. Am J Orthod Dentofacial Orthop. 1994; 106: 265-72.

9. Maltagliati LA, Feres R, Figueiredo MAF, Siqueira DF. Aesthetic brackets - clinical aspects. Rev Clín Ortodon Dental Press. 2006; 5: 89-95.

10. Swartz ML. Ceramic brackets. J Clin Orthod Boulder. 1988; 22: 82-8.

11. Aknin PC, Nanda RS, Duncanson MG, Currier F, Sinha PK. Fracture strength of ceramic brackets during arch wire torsion. Am J Orthod Dentofacial Orthop. 1996; 109: 22-7.

12. Sinha PK, Nanda RS. Esthetic orthodontic appliances and bonding concerns for adults. Dent Clin North Am. 1997; 41: 89-109.

13. Olsen ME, Bishara SE, Jakobsen JR. Evaluation of the shear bond strength of different ceramic bracket base designs. Angle Orthod. 1997;67:179-82.

14. Winchester LJ. Aesthetic brackets: to perfect or to reject? Dent Update. 1992; 19: 107-10, 112-4.

15. Phillips RW, Anusavice KJ. Physical properties of dental materials. In: Phillips RW. Dental Materials. 10. ed. Rio de Janeiro: Guanabara Koogan; 1998. p.18-27.

16. Ghafari J. Problems associated with ceramic brackets suggest limiting use to selected teeth. Angle Orthod. 1992; 62: 145-52.

17. Guignone BC. Color instability of ceramic brackets when immersed in potentially staining substances. In vitro study [dissertation]. Belo Horizonte: Pontifícia Universidade Católica de Minas Gerais; 2008. Portuguese.

18. Dietschi D, Campanile G, Holz J, Meyer JM. Comparison of the color stability of ten new-generation composites - an in vitro study. Dent Mater. 1994; 10: 353-62.

19. Sham ASK, Chu FCS, Chai J, Chow TW. Color stability of provisional Prosthodontic materials. J Prosthet Dent. 2004; 91: 447-52.

20. Lee YK. Changes in the reflected and transmitted color of esthetic brackets after thermal cycling. Am J Orthod Dentofacial Orthop. 2008; 133: 641.e1-641.e6.

21. Silva LK. Color instability of polycarbonate brackets when immersed in potentially staining substances: in vitro study [dissertation]. Belo Horizonte: Pontifícia Universidade Católica de Minas Gerais; 2008. Portuguese.

22. Bishara SE, Fehr DE. Ceramic brackets: Something old, something new, a review. Semin Orthod. 1997; 3: 178-88.
23. Karamouzos A, Athanasiou AE, Papadopoulos MA. Clinical characteristics and properties of ceramic brackets: a comprehensive review. Am J Orthod Dentofacial Orthop. 1997; 112: 34-40.

24. Fernandez $\mathrm{L}, \mathrm{Canut} J A$. In vitro comparison of the retention capacity of new aesthetic brackets. Eur J Orthod. 1999; 21: 71-7.

25. Bishara SE. Ceramic brackets: A clinical perspective. World J Orthod. 2003; 4: 61-6.

26. Filho HL, Maia LEG, Araújo MVA, Ruellas ACO. Influence of optical properties of esthetic brackets (color, translucence and fluorescence) on visual perception. Am J Orthod Dentofacial Orthop. 2012; 141: 460-7.

27. Faltamier A, Bürgers R, Rosentritt M. Bacterial adhesion of Streptococcus mutans to esthetic bracket materials. Am J Orthod Dentofacial Orthop. 2008; 133(4 Suppl): S99-103.

28. Brito RL, Silva SC, Freitas JM. Brushing techniques adopted by Periodontology disciplines of 13 dental schools in the Northeast of Brazil. Rev Periodont. 1999 [cited 2014 jun 2]; 8: 14-20. 1999 Available from: http://www.revistasobrape.com.br/arquivos/edicao anterior/ ed_maidez_99/file____1999_mai_dez_tec_esco_tec_esco.pdf]

29. Maxfield BJ, Hamdan AM, Tufekçi E, Shroff B, Best AIM, Lindauer SJ. Development of White spot lesions during orthodontic treatment: Perceptions of patients, parents, orthodontists, and general dentists. Am J Orthod Dentofacial Orthop. 2012; 141: 337-44.

30. Lima FAP. Evaluation of the plaque disclosing in the staining of two glassionomer/composite resin hybrid materiais [dissertation]. Piracicaba: Universidade Estadual de Campinas. Piracicaba Dental School; 1997. Portuguese.

31. Dorini AL. The influence of different finishing and polishing systems on two composites surface roughness and pigmentation [dissertation]. Piracicaba: Universidade Estadual de Campinas. Piracicaba Dental School; 1999. Portuguese. 